\title{
Design and Analysis of a Metallic Ogive Payload Fairing for a New Generation Launch Vehicle
}

\author{
Litty Molly Mathew ${ }^{1}$, Deepak B.P ${ }^{2}$, Basil Sabu ${ }^{3}$ \\ ${ }^{I}$ (Dept. of Civil Engineering, Mar Athanasius College of Engineering, Kerala, India) \\ ${ }^{2}$ (Scientist/Engineer, VSSC/ISRO, Kerala, India) \\ ${ }^{3}$ (Asst. Professor, Dept. of Civil Engineering, Mar Athanasius College of Engineering, Kerala, India)
}

\begin{abstract}
Launch vehicles are designed so as to travel through different layers of the atmosphere and thus are subjected to aerodynamic forces. Payload fairing, also known as heat shield is the topmost part of any launch vehicle. They are used to shield the satellites and payloads from the external atmosphere and aerodynamic forces. This paper focuses on the design and analysis of an ogive shaped payload fairing for new generation launch vehicle. Integrally stiffened panels are used as skins made of Aluminium alloy- AA2014. The design is carried out for a transonic regime Mach number of 1.2. Finite element modelling and analysis are carried out in NISA software. Based on the analysis results, mass optimization is carried out for the structure. Buckling margins and natural frequencies are estimated for the optimum configuration. A comparison with an existing composite payload fairing of similar configuration shows that their masses are comparable and hence can be considered as an alternate design option.
\end{abstract}

Keywords: Buckling, Frequency, Integrally Stiffened Panel, Ogive Payload Fairing, Stress.

\section{Introduction}

Payload Fairing (PLF) also known as heat shield is the uppermost part of a launch vehicle and is used to protect the satellite from the aerodynamic forces and external atmosphere encountered during flight. They usually consist of two separate symmetric halves connected by fasteners along length and separation system joints at the aft end. On reaching the desired altitude, the fairing structure gets jettisoned from the vehicle through these joints without affecting the trajectory of the vehicle. PLF structure experiences maximum unsteadiness at the boat-tail region during transonic regime of flight due and is subjected to large acoustic loads. Studies have shown that Ogive shape for PLF reduces drag and increase vehicle performance [1].

A typical PLF structure consists of bulkheads, longerons covered by stiffened panels. Bulkheads are transverse members which provide the bending stiffness for the PLF. Longerons are longitudinal stiffening members to provide axial stiffness for resisting the axial compressive loads and buckling. Panels are used to cover the structural framework and exposed to aerodynamic pressure and acoustic loads during various regimes of flight. Integrally stiffened panels are used in aerospace industry due to their increased structural efficiency, reduced structural mass and reduction in no. of fasteners and joints [2]. Integrally stiffened panels made of Aluminium alloys are preferred for the design of skin for aerospace structures due to the specific strength and stiffness, and manufacturing feasibility.

Modelling and analysis of a payload fairing is done in this study using NISA software. Individual structural members are modeled and stresses are extracted. Design are done based on these results. Static analysis is done to check the design specifications. Buckling load factors and frequencies are extracted. Optimisation of the structure is done based on the finite element analysis results.

\section{II.Payload Fairing Configuration}

The configuration shown in Fig. 1 shows a payload fairing for any diameter ' $\mathrm{D}$ '. This ratio is maintained to impart the required aerodynamic configuration.

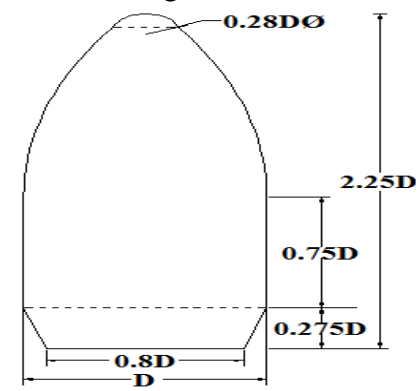

Fig.1. Payload fairing configuration 


\subsection{Design Specifications}

\section{Design of Payload Fairing}

a) The stress induced on the structural elements should be less than the yield strength of AA2014 for limit loads and less than ultimate tensile strength for ultimate loads.

b) The displacement at the tip should be limited to less than $20 \mathrm{~mm}$.

c) The failure of the structure should not take place for loads less than ultimate load.

\subsection{Preliminary Design}

Preliminary design involves the sizing of skin thickness based on aerodynamic pressure distribution. As a part of this, the PLF outer configuration is modelled and pressure co-efficients are extracted from Computational Fluid Dynamics (CFD) analysis, for a transonic regime Mach no. of 1.2. In addition to the pressure loads, inertia forces in the form of $18 \mathrm{~m} / \mathrm{s}^{2}$ (longitudinal) and $2.8 \mathrm{~m} / \mathrm{s}^{2}$ (lateral) are also applied. Limit loads are computed for the critical regions of structure as shown in Table 1. Aluminium alloy AA2014 is considered as the material for PLF structure in the design [3]. Table 2 shows the properties of AA2014.

Table 1. Limit loads

\begin{tabular}{|l|l|l|l|l|}
\hline Location & SF(kN) & BM(kNm) & AF(kN) & EAL(kN) \\
\hline Cap Aft End & 21 & 7 & 109 & 120 \\
\hline Cone Aft End & 116 & 233 & 434 & 620 \\
\hline Cylinder Aft End & 187 & 945 & 464 & 1220 \\
\hline Boat tail Aft End & 158 & 1170 & 530 & 1700 \\
\hline
\end{tabular}

Table 2. Properties of AA2014 Alloy

\begin{tabular}{|l|l|}
\hline Property & Value \\
\hline Density & $2800 \mathrm{~kg} / \mathrm{m}^{3}$ \\
\hline Elastic modulus & $68670 \mathrm{~N} / \mathrm{mm}^{2}$ \\
\hline Poisson's ratio & 0.3 \\
\hline Ultimate tensile strength & $440 \mathrm{~N} / \mathrm{mm}^{2}$ \\
\hline Tensile yield strength & $370 \mathrm{~N} / \mathrm{mm}^{2}$ \\
\hline Bearing yield strength & $440 \mathrm{~N} / \mathrm{mm}^{2}$ \\
\hline Shear strength & $235 \mathrm{~N} / \mathrm{mm}^{2}$ \\
\hline
\end{tabular}

Sizing of panels are mainly done based on the functional and manufacturing requirements. The skin is divided into 19 panels. Loads acting on each panel are determined by interpolating the limit loads at each level. The divisions of skin panels have been illustrated in Fig. 2. Panels 1 to 18 are designed as integrally stiffened machined panels whereas panel 19 is designed as a formed panel.

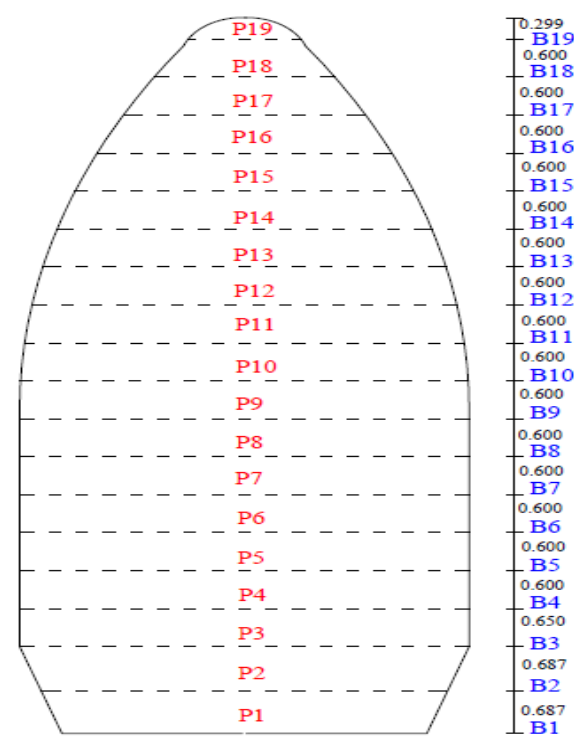

Fig. 2. Division of skin panels

\subsection{Design of Nose Cap}

Nose cap is designed as a shell structure made of AA2014. Taking into account, the meridional stress acting on the shell, a thickness of $6 \mathrm{~mm}$ is adopted [4]. 


\subsection{Design of Integrally Stiffened Panels}

Design of integrally stiffened panels is based on the standard design procedure for stiffened panels [2]. An optimum panel configuration is arrived at based on iterative studies. Thus, the skin and stringers were designed for a thickness of $1 \mathrm{~mm}$ with varying depths. Owing to the curvature and manufacturing requirements, an included angle of $3^{\circ}$ is maintained along the curvature

\subsection{Design of Bulkheads}

Bulkheads are designed as I sections between panels. For the given payload fairing, a total number of 19 bulkheads are designed based on the arrived loads. For manufacturing convenience, bulkheads along transition regions, i. e., B1, B3 and B19 are converted to C sections. Skin is attached to the bulkheads by rivets. For the initial design, beam elements are created at each bulkhead location and corresponding stresses are checked for which these bulkheads are designed. Bulkheads are optimized on account of the bending of slender beams [5]. The bulkheads are checked for interaction of multi-directional loads using interaction equations [6] and margins for structure are estimated. The designed bulkhead sections are tabulated below in Table 3 .

Table 3. Design Dimensions for Bulkheads

\begin{tabular}{|l|l|l|l|l|}
\hline Bulkhead No. & Width of flange $(\boldsymbol{b})$ & Thickness of flange $\left(\boldsymbol{t}_{f}\right)$ & Depth $(\boldsymbol{D})$ & Thickness of web $\left(\boldsymbol{t}_{\boldsymbol{w}}\right)$ \\
\hline $\begin{array}{l}\text { B1,B2,B4 to } \\
\text { B7,B10 to B14 }\end{array}$ & 120 & 12 & 280 & 8 \\
\hline B3,B8 and B9 & 130 & 12 & 350 & 8 \\
\hline B15 and B16 & 90 & 12 & 250 & 8 \\
\hline B17 and B18 & 80 & 10 & 200 & 6 \\
\hline B19 & 75 & 6 & 160 & 4 \\
\hline
\end{tabular}

\subsection{Design of Longerons}

Design of longerons is similar to bulkheads. Four $\mathrm{T}$ shaped longerons are provided along the longitudinal direction with an included angle of $90^{\circ}$. Beam sections are created along these regions and the loads are computed for the sections. Table 4 shows the dimensions of designed longerons.

Table 4. Design Dimensions for Longerons

\begin{tabular}{|l|l|l|l|l|}
\hline Longeron & Width of flange $(\boldsymbol{b})$ & Thickness of flange $\left(\boldsymbol{t}_{f}\right)$ & Depth $(\boldsymbol{D})$ & Thickness of web $\left(\boldsymbol{t}_{\boldsymbol{w}}\right)$ \\
\hline L1 to L4 & 60 & 10 & 80 & 6 \\
\hline
\end{tabular}

\section{Finite Element Modelling}

Finite element model is generated in NISA software [7]. First, the skin is modeled using 4 noded 3D general shell element of NKTP 20. They are so meshed to get 360 elements along the width. Later, 19 bulkheads are modelled at corresponding levels and merged into the skin. Shell elements are used for bulkheads. Bulkheads at cylinder-boat tail region, fore end and aft end are modelled as $\mathrm{C}$ section. Now, stringers are modelled using 2 noded 3D beam element of NKTP 12 in between bulkheads and merged to the skin. Longerons are modelled as beam sections similar to stringers and merged to skin [8]. Pressure distribution from CFD results is applied on the skin elements. Inertia forces are applied as body forces. Boundary conditions are provided with three translational constraints per node along the boat tail aft end region. Finally, the model is checked for element skewness, duplication and singularity. An isometric view of model is shown in Fig. 3(a). Loads acting on the structure are shown in Fig. 3(b).
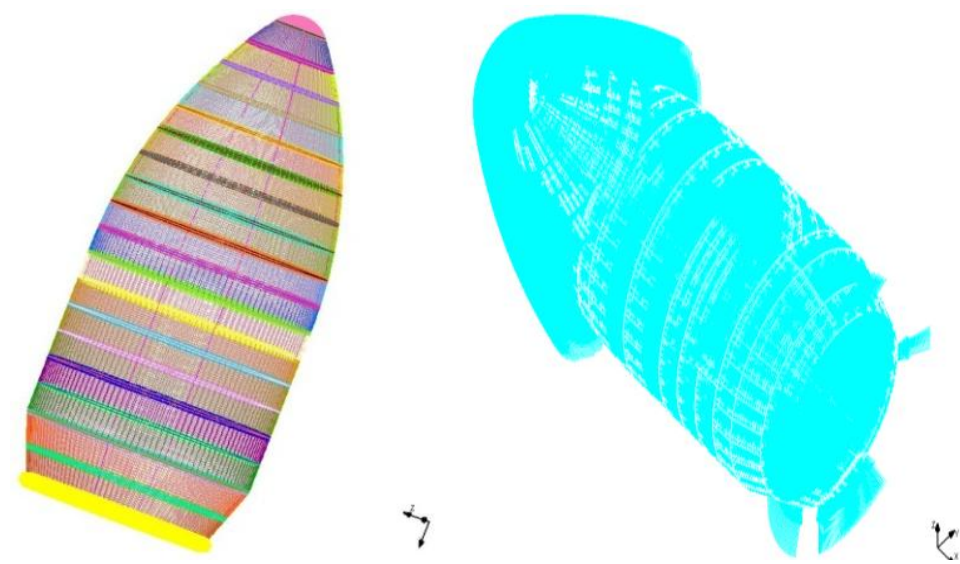

Fig. 3.(a) Isometric view of payload fairing (b) Load acting on the structure 


\section{Optimization Studies for Payload Fairing}

Preliminary finite element analysis of the designed payload fairing showed a deformation of $19.5 \mathrm{~mm}$ with a maximum von Mises stress of only $83.8 \mathrm{~N} / \mathrm{mm}^{2}$ acting on the bulkheads. Hence further structural optimization studies are carried out for arriving at least mass configuration with constraint as maximum von Mises stress and displacement within allowable limits. Parametric studies are carried out by reducing the thickness of flanges and webs of bulkheads, by varying the number of bulkheads, by varying the shape of bulkheads, number of stringers and varying skin thickness. The final configuration of the optimized model is tabulated below in Table 5 .

Table 5. Optimized Section of Bulkheads

\begin{tabular}{|l|l|l|l|l|l|}
\hline Bulkhead Id & Width of flange $(\boldsymbol{b})$ & Thickness of flange $\left.\boldsymbol{(}_{\boldsymbol{f}}\right)$ & Depth $(\boldsymbol{D})$ & Thickness of web $\left(\boldsymbol{t}_{\boldsymbol{w}}\right)$ & Section type \\
\hline B1 & 90 & 4 & 140 & 3 & C \\
\hline $\begin{array}{l}\text { B2,B4 to } \\
\text { B7and B10 to } \\
\text { B14 }\end{array}$ & 90 & 4 & 105 & 3 & T \\
\hline B3 & 90 & & & & \\
\hline B8 and B9 & 100 & 4 & 140 & 3 & Double C \\
\hline B15 to B18 & 85 & 4 & 175 & 3 & I \\
\hline B19 & 75 & 4 & 85 & 3 & T \\
\hline
\end{tabular}

The optimized design for PLF has a skin thickness of $2.2 \mathrm{~mm}$ and stringer thickness of $2 \mathrm{~mm}$. This was done to increase margins against buckling. The mass of the structure was found to be $1389 \mathrm{~kg}$.

\subsection{Linear Static Analysis}

\section{Results and Discussions}

The optimized structure is subjected to static analysis and stresses and displacements on structure are extracted. The structure experiences a maximum tip displacement of $15.89 \mathrm{~mm}$ and a maximum Von Mises stress of $237.8 \mathrm{~N} / \mathrm{mm}^{2}$, which is below the yield strength of AA2014. The maximum stress is found to occur at the cylinder boat tail transition region. This is can be justified by the sharp and sudden change in shape which causes higher stresses in that area. Fig. 4 shows the maximum tip displacement and Von Mises stress acting on the structure.
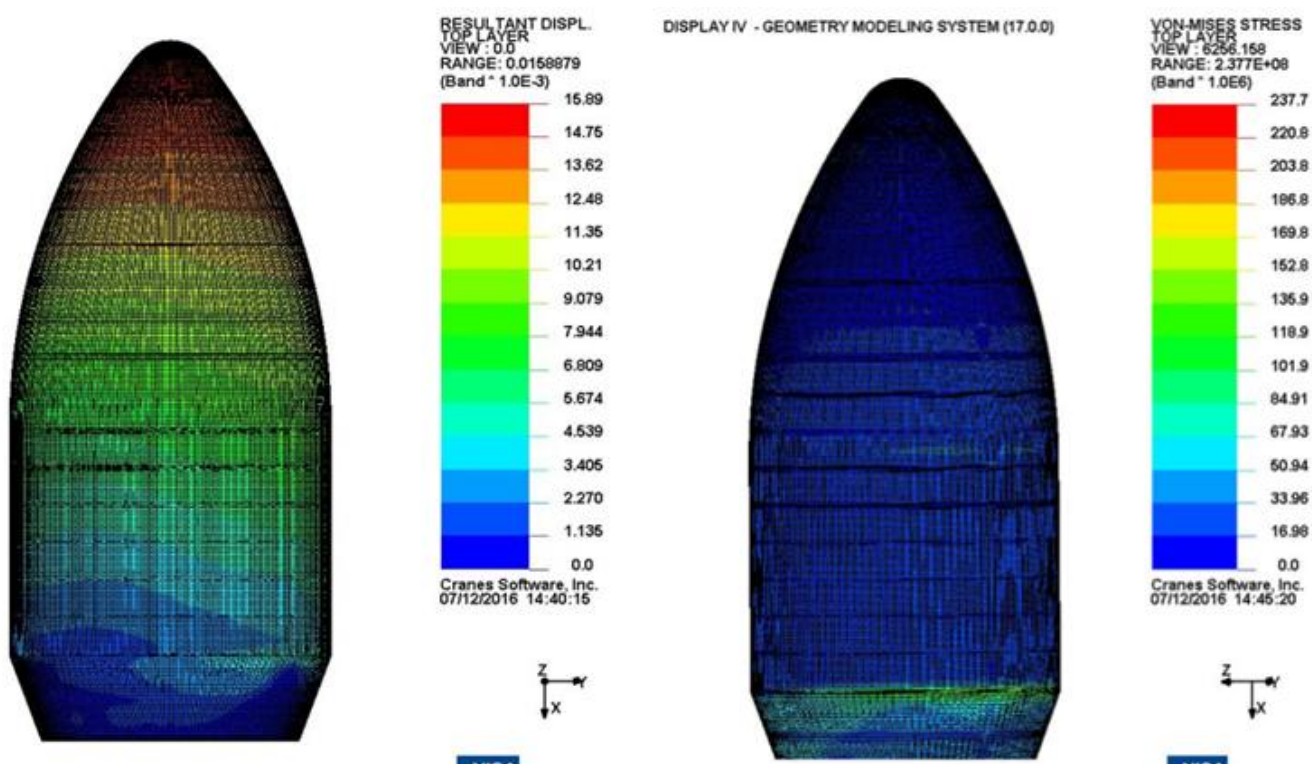

Fig. 4.(a) Maximum tip displacement (b) von - Mises stress acting on structure

\subsection{Buckling Analysis}

Buckling analysis was carried out for the optimized model and the buckling load factor was found to be 1.03. The buckling load factors with corresponding mode shapes upto three eigen value was computed. Fig. 5(a) shows the buckling load factor and corresponding mode shape for first eigen value. The results show that the structure has a minimum margin of $3 \%$ on buckling. The buckling mode observed is a kind of local buckling of the skin around the nose cone top region. This can be justified by the fact that the geometry has maximum curvature along that region. 


\subsection{Free Vibration Analysis}

Natural frequencies of PLF for first three modes were computed. The natural frequency for first mode shape is found to be $20 \mathrm{~Hz}$. Fig.5(b) shows first frequency and corresponding mode shape. Frequency of PLF structure is well away from control system frequency.

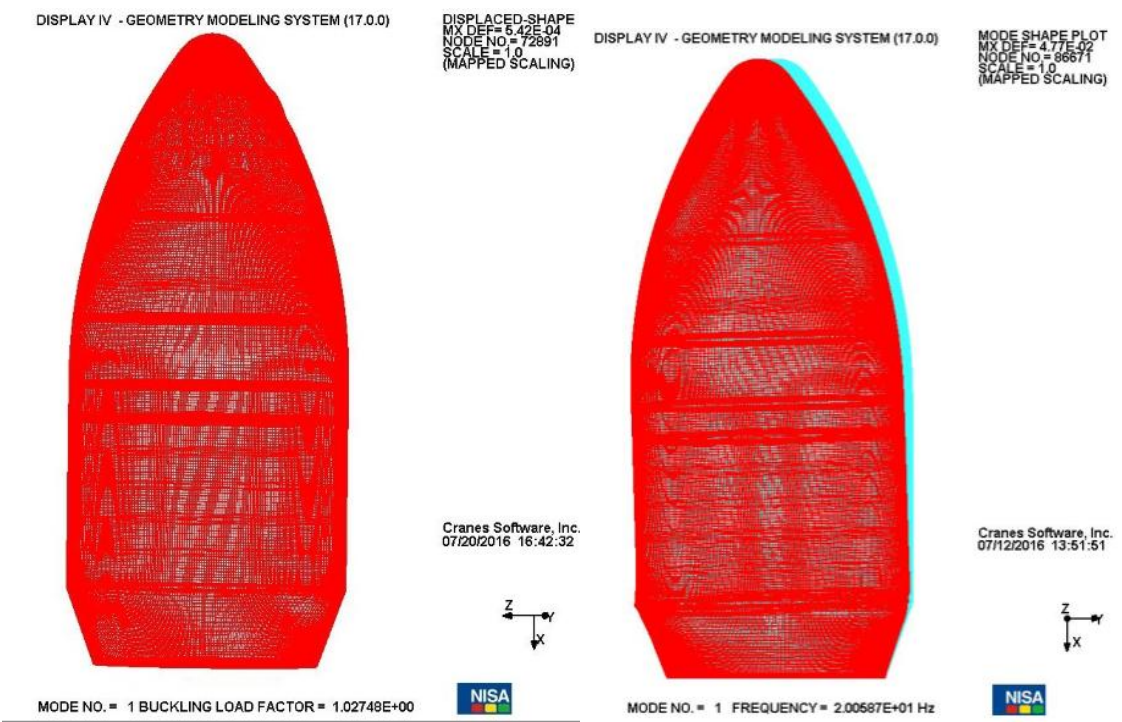

Fig. 6. (a) Buckling mode shape for first mode (b) First mode frequency

\subsection{Comparison Study}

A comparison study based on mass is done with an existing composite payload fairing of the same configuration. Composites are mainly used for their reduction in mass. The structural components are made of CFRP composites which are assembled with aluminium interfaces rings. The mass of the composite structure is $1250 \mathrm{~kg}$. That is, the mass of the metallic payload fairing designed is only $139 \mathrm{~kg}$ more than the composite version and hence comparable. Hence, it can be concluded that the designed payload fairing meets the structural specifications for PLF and with acceptable mass penalty.

\section{Conclusions}

The design and analysis of an ogive payload fairing is carried out for the specifications. Mass optimization studies are conducted to arrive at a least mass configuration. Static analysis was carried out on the optimized structure and the displacements and stresses were found to be acceptable. The maximum von Mises stress acting on the structure was found to be $237.8 \mathrm{~N} / \mathrm{mm}^{2}$. Buckling load factor of the structure is 1.03 . The first mode frequency is $20 \mathrm{~Hz}$. Comparison with a composite fairing shows that the masses are comparable and thus the metallic version of payload fairing can be considered as a design alternative for PLF structures.

Taking these conclusions as a reference, analysis can to be done for different Mach No:s. The design of separation joints can be done. Further, dynamic analysis can be done to study the vibration characteristics.

\section{References}

[1] Irish Angelin S, Aerodynamic shaping of payload fairing for a launch vehicle, International Journal of Engineering and Science Research,4(5), 2014.

[2] Michael Niu, Airframe Stress Analysis and Sizing, (Hong Kong Conmilit Press Ltd -1999).

[3] T.H.G. Megson, Aircraft Structures for Engineering Students, (Butterworth Heinmann Publishers-1990).

[4] Warren C. Young and Richard G. Budynas, Roarks Formulas for Stress and Strain, (McGraw-Hill Publishing Company - 2002).

[5] David W.A Rees, Mechanics of Optimal Structural Design Minimum Weight Structures, (John Wiley and Sons Publication - 2009).

[6] E.F.Bruhn, Analysis and Design of Fight Vehicle Structures, (Gran Corporation - 2008).

[7] NISA II: Users Manual, Choice of Civil and Structural Engineers World Wide, Cranes Software International Ltd, 2001.

[8] [Nithin S Gokhale, Practical Finite Element Analysis,(Finite to Infinite - 2007). 